\title{
Constitutive Model for High Strength Concrete (HSC) at Elevated Temperatures
}

\author{
Robert Y. Xiao and Samson Ezekiel
}

\begin{abstract}
The response of concrete structures under fire is very important as fire represents as an extreme loading and severe environmental condition to a structure. The use of High Strength Concrete (HSC) in concrete construction is getting very popular now. There is an increased focus on the use of numerical methods and performance based fire design on concrete structures, which requires a temperature dependent material relationship. In this paper, a constitutive temperature dependent material model for HSC under fire is presented. Temperature dependent compressive strength, tensile strength, elastic modulus, peak strain and stress-strain relationships are discussed and identified. The model describes the variation of these properties at elevated temperatures and can be implemented into finite element software for analysis of HSC systems under fire. The proposed model is then compared with the experimental data collected and the existing models proposed by other researchers on conventional concrete and HSC. It shows close agreement with the test data and being more straightforward and simple for the numerical implementation than that of other HSC models.
\end{abstract}

Index Terms-High strength concrete, elevated temperatures, fire, constitutive model, stress-strain relationship.

\section{INTRODUCTION}

Fire safety is a main requirement for modern structure designs. It is necessary to provide adequate fire safety measures for a structural system as fire represents a major hazardous and extreme loading conditions to which a structure might be exposed to within its life time duration. A structure subjected to elevated temperatures in fire is expected to keep its integrity, maintain its load bearing capacity for a certain period of time as well as to prevent and delay the spread of the fire to the surrounding environment. Currently, fire safety design of concrete structures is achieved based on the prescriptive approach and fire ratings, of which have been set up on standard fire tests and empirical methods [1]. This approach has clear major shortcomings: being expensive, size limitation on the specimen to be tested, time consuming and sometimes it does not provide an actual representation and evaluation of the whole structure under fire. There has been a major push recently to use the performance based and numerical method for a better analysis and fire design of concrete structures instead.

Manuscript received March, 14 2013; revised May 23, 2013.

The authors are with Department of Urban Engineering at London Southbank University, London SE1 0AA UK (email: xiaor2@1sbu.ac.uk, samsone@1sbu.ac.uk).
Therefore, major codes of practice are moving towards the use of this approach, which requires a temperature dependent constitutive material model and the properties of concrete to be established to have a better representation on its behaviour under fire and elevated temperatures [2], [3]. These properties are compressive strength, tensile strength, elastic modulus, creep strain, peak strain, thermal expansion, thermal conductivity and specific heat capacity. Concrete subjected to elevated temperatures in fire experiences a decrease in compressive strength, tensile strength, elastic modulus, an increase in peak strain and a change in the stress - strain relationship [4], [5]. Some models have been proposed for compressive strength, tensile strength, elastic modulus, peak strain and stress - strain relationship for normal strength concrete (NSC) at elevated temperatures but only a few models are available for high strength concrete (HSC) under fire. The use of HSC is gaining popularity in the construction industry, HSC performs differently when compared with NSC under fire. HSC loses compressive strength and elastic modulus at a faster rate and is more susceptible to spalling than NSC [6]. Hence, it is important that these properties are better represented for numerical analysis.

In this paper, temperature dependent material properties for high strength concrete (HSC) proposed can be used to simulate the performance of HSC members and systems under fire with performance based designs and numerical methods.

\section{COMPRESSIVE StRENGTH OF HSC AT ElEVATED TEMPERATURES}

Compressive strength of concrete is the most important property of concrete and it decreases at elevated temperatures [7]. HSC retains about $70-80 \%$ of its original compressive strength at $300-400^{\circ} \mathrm{C}$ and retains about $20 \%$ at $800^{\circ} \mathrm{C}$ [8], [9]. Sancak et al. [10] reported that HSC retains $60 \%$ to $79 \%$ of its original compressive strength at $400^{\circ} \mathrm{C}$ and at $800^{\circ} \mathrm{C}$ it retains $3 \%$ to $13 \%$. Table I lists some of the well-established models for the compressive strength of concrete at elevated temperatures, most of which are for NSC. In this study a generalised model for compressive strength of HSC was developed based on regressive analysis of test data collected from [8]-[14]. The proposed relationship is given in (1). Fig. 1 shows a comparison with other models listed in Table I. The proposed model has three crucial temperature zones which reflect the design needs and main concrete behaviour changes in fire. It has an index form of temperature change which is convenient for both manual design calculations and computational analysis. 
$f_{c T}=f_{c 0}\left[\begin{array}{lc}1-0.00085(T-20) & 20^{\circ} \mathrm{C} \leq T \leq 300^{\circ} \mathrm{C} \\ \left(\begin{array}{cc}0.9417-\frac{1.379}{10^{6}} T^{2} \\ -\frac{0.1029}{10^{12}} T^{4}+\frac{0.5497}{10^{18}} T^{6}\end{array}\right) & T>1000^{\circ} \mathrm{C}\end{array}\right]$

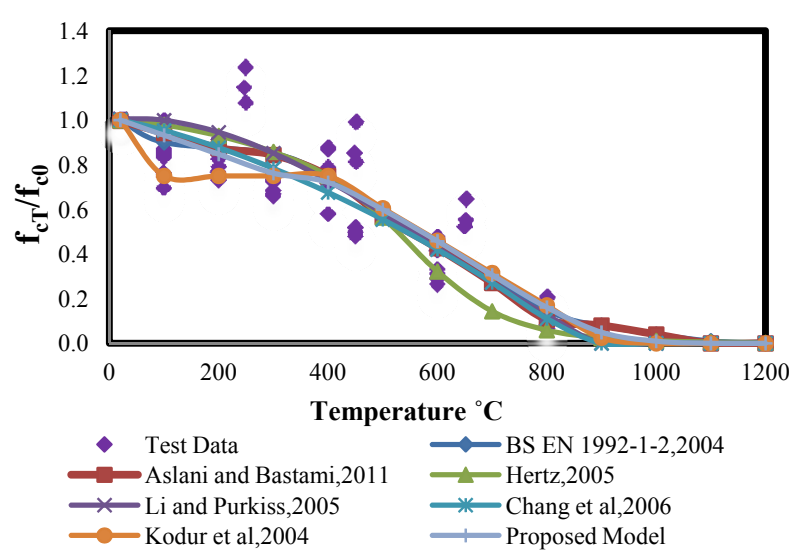

Fig. 1. Comparison between the proposed models for compressive strength of HSC with test data and other models.

\section{Tensile Strength of HSC at Elevated TEMPERATURES}

The tensile strength of HSC decreases with high temperatures but it retains about $70-75 \%$ of its unfired tensile strength at $300^{\circ} \mathrm{C}$ [3]. Xu et al. [14] reported from their study that at $450^{\circ} \mathrm{C}$ HSC retains $50-66 \%$ of its original tensile strength and at $800^{\circ} \mathrm{C}$ it only retains $11-$ $15 \%$.
Data analysis performed on the available test data collected from $[8,14]$ has produced the tensile strength of HSC at elevated temperatures in (2). Fig. 2 shows the comparison with other existing models listed in Table II. This follows the same trend as in (1) for compressive concrete strength description.

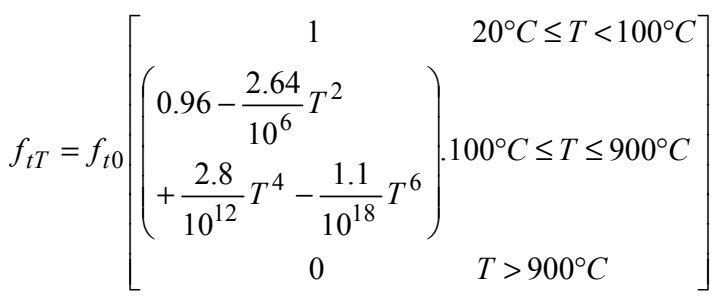

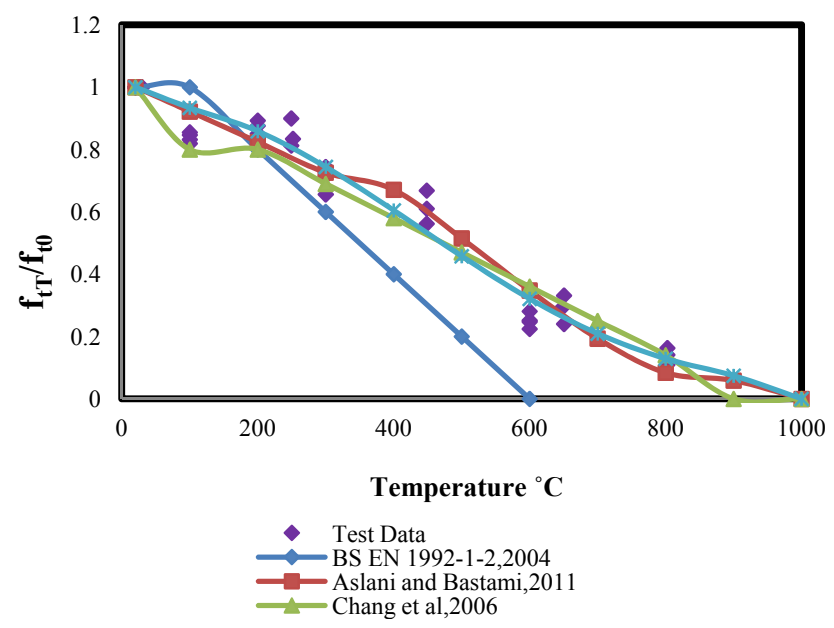

Fig. 2. Comparison between the proposed models for tensile strength of HSC with test data and other models.

TABLE I: MODELS FOR COMPRESSIVE STRENGTH OF CONCRETE AT ELEVATED TEMPERATURES

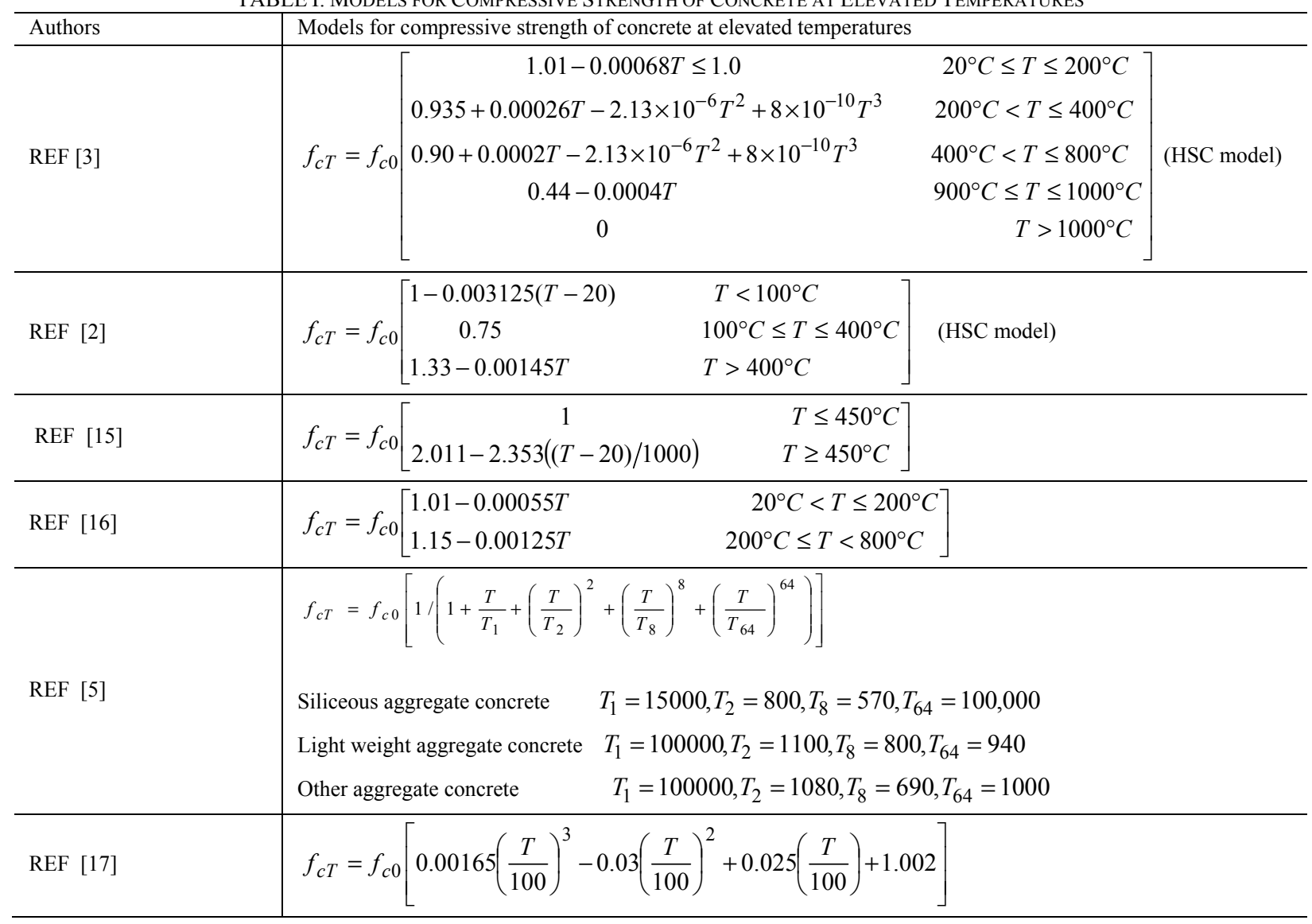


TABLE II: MODELS FOR TENSILE STRENGTH OF CONCRETE AT ELEVATED TEMPERATURES

\begin{tabular}{|c|c|c|c|c|c|}
\hline Authors & \multicolumn{5}{|c|}{ Models for Tensile Strength of Concrete at Elevated Temperatures } \\
\hline REF [3] & $f_{t T}=f_{t 0}$ & {$\left[\begin{array}{r}1.02 \\
0.965-0.0001 T-9 \times\end{array}\right.$} & $\begin{array}{l}00098 T \leq 1.0 \\
{ }_{0}^{-7} T^{2}-3 \times 10^{-9} T^{3}+3.2 \times 10^{-12} T^{4}\end{array}$ & $\left.\begin{array}{r}20^{\circ} \mathrm{C}<T \leq 300^{\circ} \mathrm{C} \\
300^{\circ} \mathrm{C}<T \leq 900^{\circ} \mathrm{C} \\
T \geq 1000^{\circ} \mathrm{C}\end{array}\right]$ & (HSC model) \\
\hline REF [16] & $f_{t T}=f_{t 0}$ & $\begin{array}{l}1.05-0.0025 T \\
0.80 \\
1.02-0.0011 T \geq 0.0\end{array}$ & $\left.\begin{array}{r}20^{\circ} \mathrm{C} \leq T \leq 100^{\circ} \mathrm{C} \\
100^{\circ} \mathrm{C}<T \leq 200^{\circ} \mathrm{C} \\
200^{\circ} \mathrm{C}<T \leq 800^{\circ} \mathrm{C}\end{array}\right]$ & & \\
\hline
\end{tabular}

\section{Elastic Modulus of HSC at Elevated TEMPERATURES}

Concrete stiffness and elastic modulus decrease at elevated temperatures. HSC retains $35-43 \%$ of its elastic modulus at $400^{\circ} \mathrm{C}$ and about $5 \%$ at $800^{\circ} \mathrm{C}$ [9], [11]. The model proposed for elastic modulus of HSC at elevated temperatures was derived from the test data from [9], [11]. The presented model is expressed in (3). Fig. 3 shows the comparison between other published models summarised in Table III.

$E_{c T}=E_{c 0}\left[\begin{array}{cc}\left(\begin{array}{l}0.992-\frac{3.176}{10^{6}} T^{2} \\ +\frac{3.3393}{10^{12}} T^{4}-\frac{1.1513}{10^{18}} T^{6}\end{array}\right) 20^{\circ} \mathrm{C} \leq T<800^{\circ} \mathrm{C} \\ 0.026-2.5 \times 10^{-5} T & 800^{\circ} \mathrm{C} \leq T \leq 1000^{\circ} \mathrm{C} \\ 0 & T>1000^{\circ} \mathrm{C}\end{array}\right]$

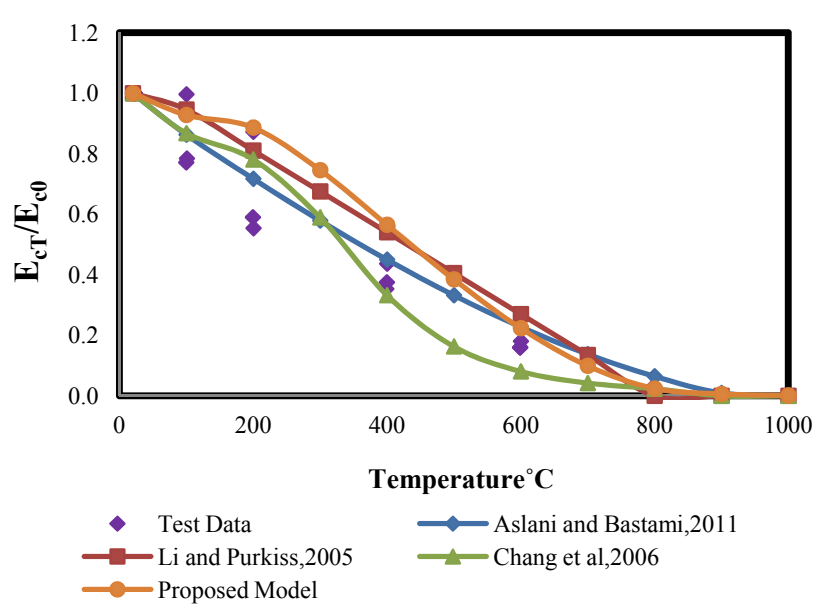

Fig. 3. Comparison between the proposed models for elastic modulus of HSC with test data and other models.

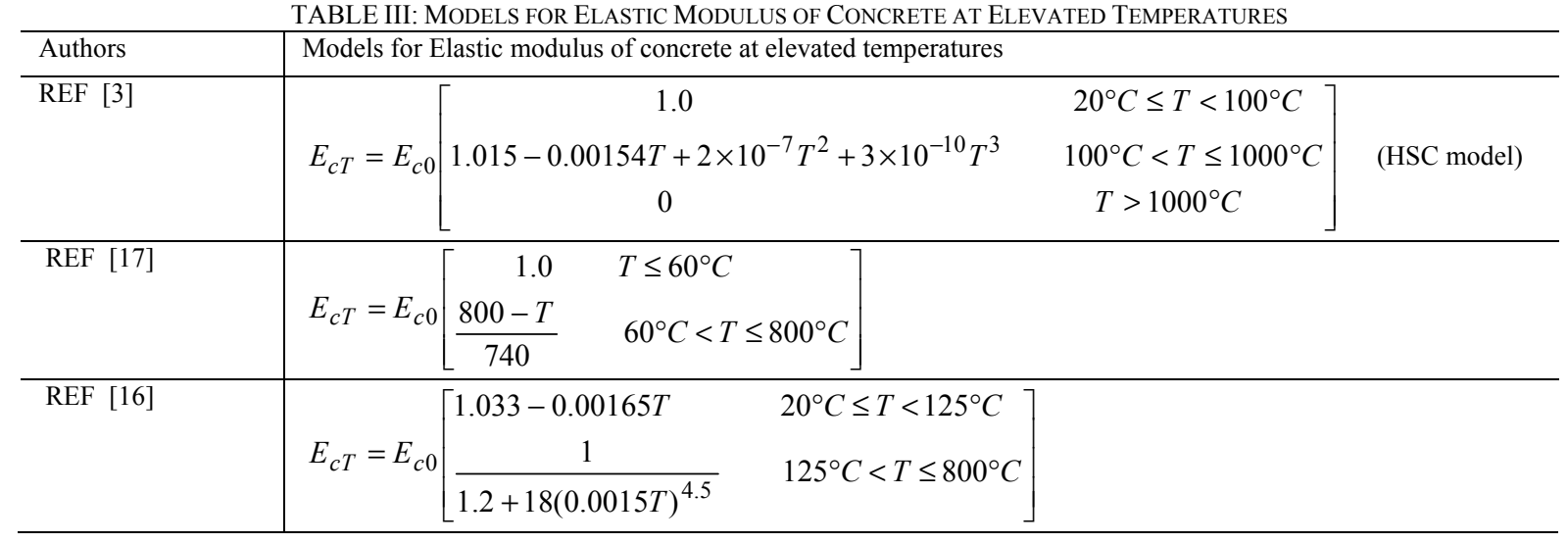

\section{Peak Strain of HSC at Elevated Temperatures}

Concrete's peak strain increases at elevated temperatures due to the decrease in stiffness and loss of strength. Data for peak strain of high strength concrete at elevated temperatures was collected from [9] and a temperature dependent relationship for peak strain was proposed. The model is expressed as (4). Fig. 4 shows the difference between other models listed in Table IV.

$$
e_{c T}=e_{c 0}\left[\begin{array}{cl}
1 & 20^{\circ} \mathrm{C} \leq T \leq 200^{\circ} \mathrm{C} \\
\frac{1}{1.171-8.704 \times 10^{-5} T^{1.402}} & 200^{\circ} \mathrm{C}<T \leq 800^{\circ} \mathrm{C} \\
8 & T>800^{\circ} \mathrm{C}
\end{array}\right]
$$

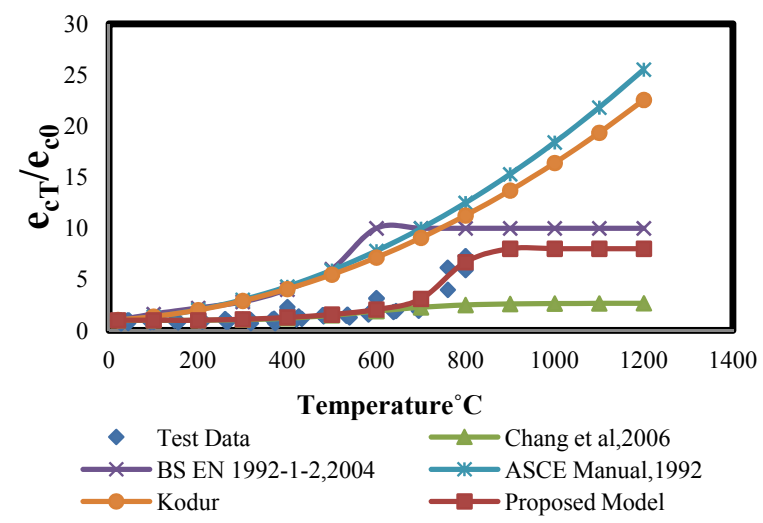

Fig. 4. Comparison between the proposed models for peak strain of HSC with test data and other models. 


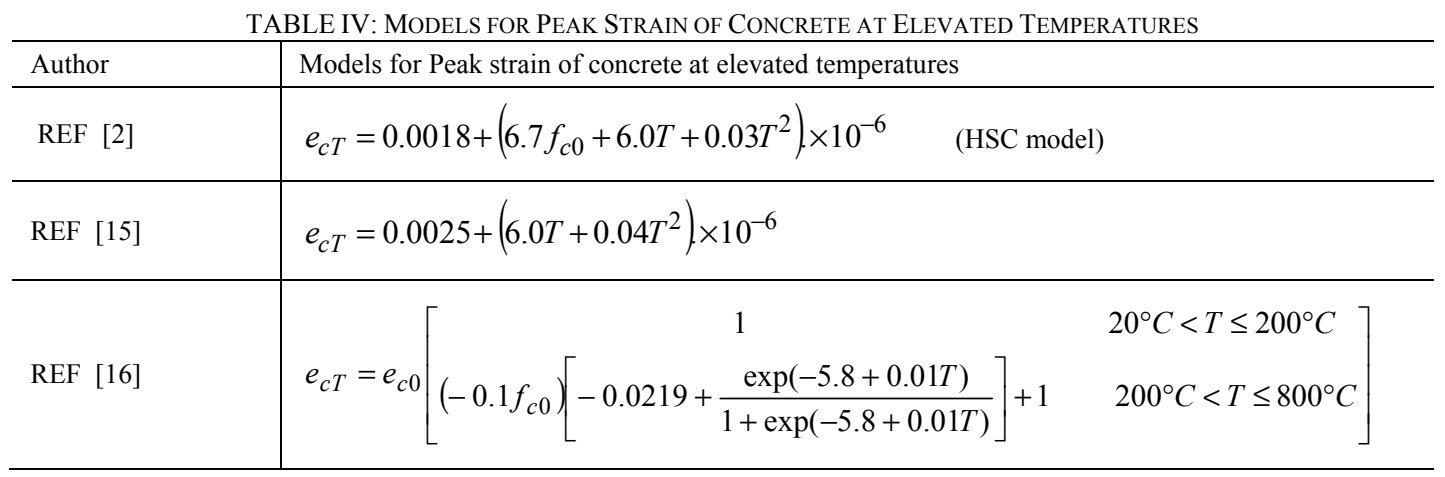

TABLE V: MODELS FOR STRESS- STRAIN RELATIONSHIP OF CONCRETE AT ELEVATED TEMPERATURES

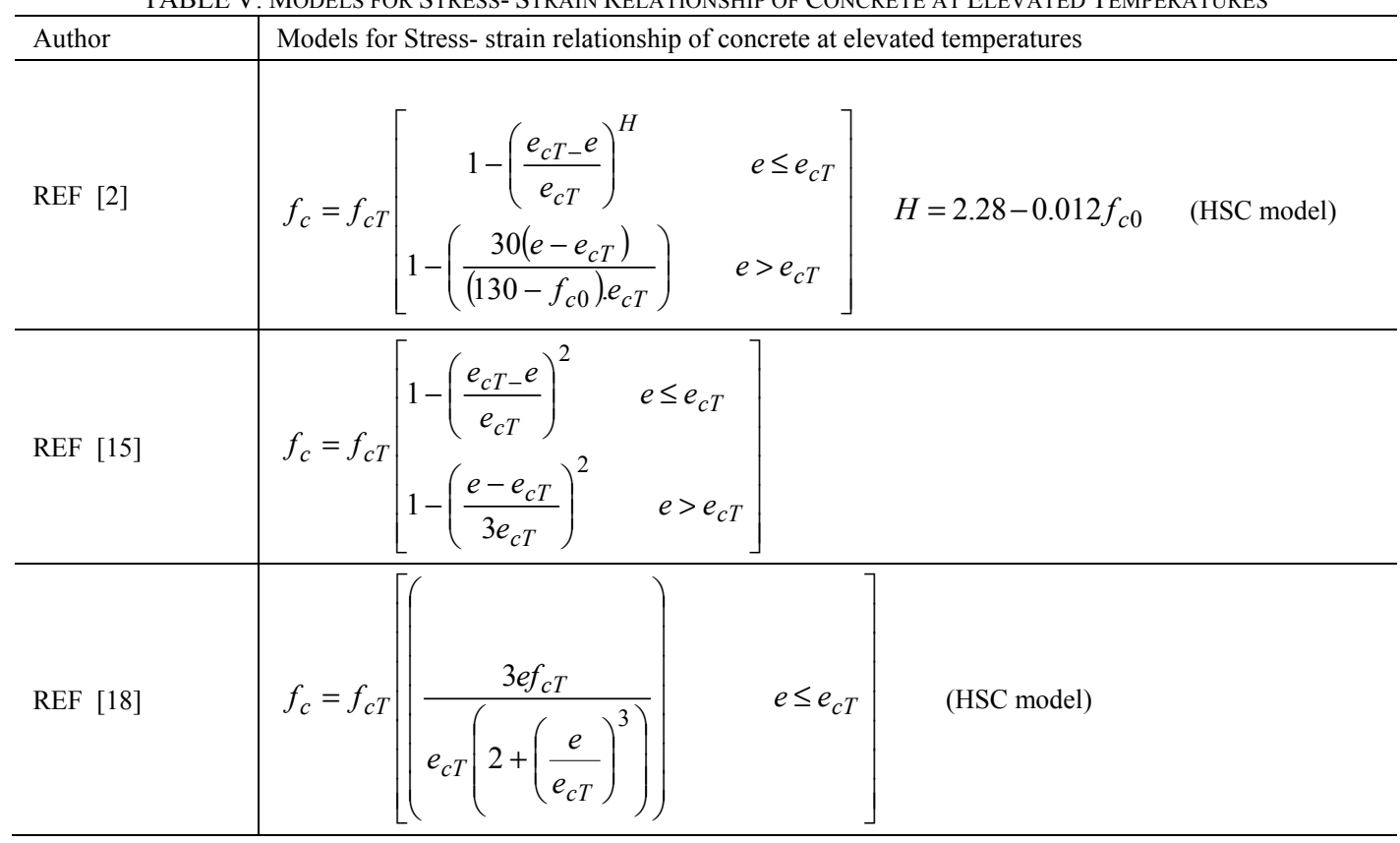

\section{COMPRESSIVE STRESS-STRAIN RELATIONSHIP OF HSC AT ELEVATED TEMPERATURES}

For the complete stress-strain property of high strength concrete under elevated temperatures data was collected from [9], [13]. The stress strain curve model was proposed as in (5) which are based on the test data collected. Fig. 5 shows the comparison with other available models listed in Table V.

$$
f_{c}=f_{c T}\left[\begin{array}{ll}
1.7425\left(\frac{e}{e_{c T}}\right)-0.7437\left(\frac{e}{e_{c T}}\right)^{2.4119} & e \leq e_{c T} \\
1.0275\left(\frac{e}{e_{c T}}\right)^{-1.7356}-0.0114\left(\frac{e}{e_{c T}}\right) & e>e_{c T}
\end{array}\right]
$$

\section{NOTATIONS}

e Strain of concrete due to applied compressive stress

$e_{c 0} \quad$ Peak strain of concrete at ambient temperature

$e_{c T} \quad$ Peak strain of concrete at elevated temperature

$E_{c 0} \quad$ Elastic modulus of concrete at ambient temperature

$E_{c T}$ Elastic modulus of concrete at elevated temperature $f_{c} \quad$ Applied compressive stress

$f_{c 0} \quad$ Compressive strength of concrete at ambient temperature

$f_{c T} \quad$ Compressive strength of concrete at elevated temperature

$f_{t 0} \quad$ Tensile strength of concrete at ambient temperature

$f_{t T} \quad$ Tensile strength of concrete at elevated temperature

\section{Discussion OF RESUlt}

The model proposed for HSC at elevated temperatures fits well with the test data and shows good agreement with other models. Compressive strength, tensile strength and elastic modulus models were in the form of a higher order polynomial shape, which best fits the test data collected. The models have described the deterioration of these properties under elevated temperatures being in polynomial trend. The model proposed are accurate compared with the test results. At $800^{\circ} \mathrm{C}$ the concrete losses about $90 \%$ of its stiffness and strength so it is assumed that above this temperature the concrete has failed and there is less variation in the peak strain. 

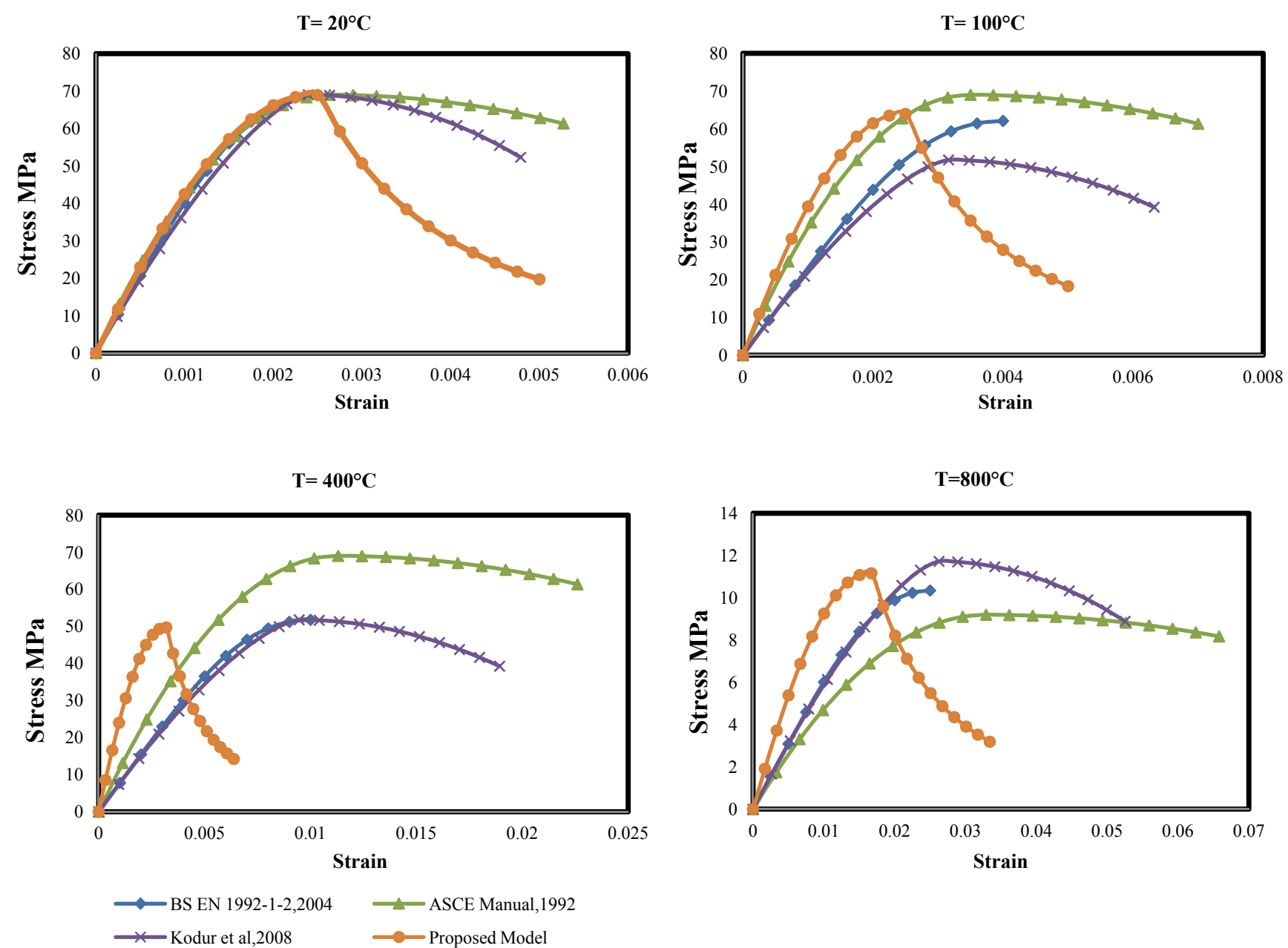

Fig. 5. Comparison between the proposed models for Stress-strain relationship of HSC with test data and other model

\section{CONCLUSIONS}

The following conclusions can be drawn from this research:

1) The proposed models for the compressive strength, tensile strength and elastic modulus for HSC fit well with the experimental results obtained and also show close agreement with other existing models for HSC.

2) The proposed model for the peak strain of HSC fits well with the experimental data and shows close agreement with the Eurocode model. The model shows some variation with ASCE [15] and the Kodur et al. [2] model.

3) At ambient temperature the presented model for stressstrain relationship of HSC shows close agreement with other models but as the temperature increases the model shows some variation with the other models, this can be attributed to the variation of the peak strain of different models. The ASCE [15] model shows more variation to the presented model, this can be attributed to the higher rate of loss of strength of high strength concrete when compared to normal strength concrete.

4) The proposed models have three crucial temperature zones which reflect the practical design needs and main concrete behaviour changes in fire and it becomes simple for both manual design calculations and FE computational analysis.

5) The proposed models can be implemented into the Finite Element software to perform the analysis of structural systems subjected to elevated temperatures in fire.

\section{ACKNOWLEDGEMENT}

The authors are grateful for a grant provided by the Petroleum Technology Fund, Nigeria of which is supporting a $\mathrm{PhD}$ research conducted at London South Bank University by Mr Samson Ezekiel.

\section{REFERENCES}

[1] J. A. Purkiss, Fire Safety Engineering Design of Structures, Oxford: Butterworth-Heinemann, 1996.

[2] V. K. R. Kodur, M. M. S. Dwaikat, and M. B. Dwaikat, "Hightemperature properties of concrete for fire resistance modeling of structures," ACI Material Journal, vol. 105, pp. 517-527, 2008.

[3] F. Asalani and M. Bastami, "Constitutive relationships for normal and high-strength concrete at elevated temperatures," ACI Material Journal, vol. 108, pp. 355-364, 2011.

[4] M. A. Youssef and M. Moftah, "General stress-strain relationship for concrete at elevated temperatures," Eng. Struct., vol. 29, pp. 26182634, 2007.

[5] K. Hertz D, "Concrete strength for fire safety design," Magazine of Concrete Research, vol. 57, pp. 445-453, 2005. 
[6] V. K. R. Kodur, "Fire Performance of High-Strength Concrete Structural Members," Construction Technology Update, vol. 31, pp. 1-4, 1999.

[7] M. Bastami and F. Aslani, "Preloaded high temperature constitutive models and relationships for concrete," Scientia Iranica, vol. 17, pp. $11-25,2010$.

[8] A. Behnood and M. Ghandehari, "Comparison of compressive and splitting tensile strength of high-strength concrete with and without polypropylene fibers heated to high temperatures," Fire Saf. J., vol. 44, pp. 1015-1022, 11, 2009.

[9] F. Cheng, V. K. R. Kodur and T. Wang, "Stress-strain curves for high strength concrete at elevated temperatures," J. Mater. Civ. Eng., vol. 16, pp. 84-90, January/February 2004.

[10] E. Sancak, Y. Dursun Sari, and O. Simsek, "Effects of elevated temperature on compressive strength and weight loss of the lightweight concrete with silica fume and superplasticizer," Cement and Concrete Composites, vol. 30, pp. 715-721, 2008.

[11] Y. F. Fu, Y. L. Wong, C. S. Poon, and C. A. Tang, "Stress-strain behaviour of high-strength concrete at elevated temperatures," Magazine of Concrete Research, vol. 57, pp. 535-544, 2005.

[12] L. Phan and N. Carino, "Code provisions for high strength concrete strength-temperature relationship at elevated temperatures," Materials and Structures, vol. 36, pp. 91-98, 2003.

[13] C. S. Poon, Z. H. Shui and L. Lam, "Compressive behavior of fiber reinforced high-performance concrete subjected to elevated temperatures," Cem. Concr. Res., vol. 34, pp. 2215-2222, 2004.

[14] Y. Xu, Y. L. Wong, C. S. Poon, and M. Anson, "Influence of PFA on cracking of concrete and cement paste after exposure to high temperatures," Cem. Concr. Res., vol. 33, pp. 2009-2016, 2003.

[15] T. T. Lie, "Structural fire protection," American Society of Civil Engineers, New York, Tech. Rep. no.78, 1992.

[16] Y. F. Chang, Y. H. Chen, M. S. Sheu, and G. C. Yao, "Residual stress-strain relationship for concrete after exposure to high temperatures," Cem. Concr. Res., vol. 36, no. 10, pp. 1999-2005, 2006.

[17] L. Li and J. Purkiss, "Stress-strain constitutive equations of concrete material at elevated temperatures," Fire Saf. J., vol. 40, no. 7, pp. 669-686, 2005.

[18] European Committee for Standardization, "Eurocode 2: Design of concrete structures - Part 1-2: General rules - structural fire," BSI, Tech. Rep. BS EN 1992-1-2:2004, 2004.

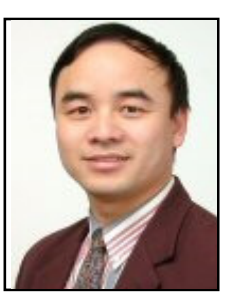

Engineers.

He obtained his PhD from the University of Nottingham, UK. His research interests are on composite materials, composite structures, steel structures and the computational simulation by finite element analysis. The author of one patent, over 140 journal and international conference papers and many research reports.

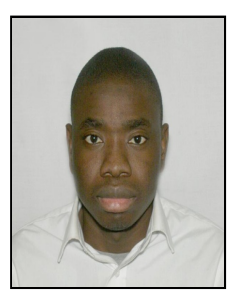

Samson Ezekiel is a member of the American Concrete Institute (ACI). He is currently carrying out his $\mathrm{PhD}$ research on concrete and fire simulations. He has obtained a Masters (MSc) degree in Civil Engineering at London Southbank University with a distinction and Bachelors of Engineering degree in Civil Engineering at the Federal University of Technology Minna, Nigeria. $\mathrm{He}$ has research interests in design of concrete structures, material modeling and simulations of structures under fire. 